\title{
Interactive effects of granulosa cell apoptosis, follicle size, cumulus-oocyte complex morphology, and cumulus expansion on the developmental competence of goat oocytes: a study using the well-in-drop culture system
}

\author{
Zheng-Bin Han, Guo-Cheng Lan, Yan-Guang Wu, Dong Han, Wei-Guo Feng, Jun-Zuo Wang and \\ Jing-He Tan \\ Laboratory for Animal Reproduction and Embryology, College of Animal Science and Veterinary Medicine, Shandong \\ Agricultural University, Tai-an City, Shandong 271018, People's Republic of China
}

Correspondence should be addressed to J-H Tan; Email: tanjh@sdau.edu.cn

\begin{abstract}
Using a well-in-drop (WID) oocyte/embryo culture system that allows identification of follicular origin, we have investigated the effects of granulosa cells (GCs) apoptosis, follicle size, cumulus-oocyte complexes (COCs) morphology, and cumulus expansion on the developmental competence of goat oocytes matured and cultured individually following parthenogenetic activation. The WID system supported oocyte maturation and embryo development to a level similar to the conventional group system. The majority of goat oocytes acquired competence for development up to the 8-16 cell stage in follicles larger than $2 \mathrm{~mm}$, but did not gain the ability to form morula/blastocyst $(\mathrm{M} / \mathrm{Bs})$ until follicles larger than $3 \mathrm{~mm}$ in diameter. The extent of atresia affected $\mathrm{M} / \mathrm{Bs}$ formation. This effect varied according to the follicle size. Cumulus expansion increased with follicle size and decreased with increasing incidence of GCs apoptosis. Oocyte developmental potential was also correlated with cumulus expansion. Regardless of the degree of follicle atresia, $\mathbf{7 3 - 8 4 \%}$ of the floating cells in the follicular fluid (FF) underwent apoptosis. Correlation between floating cell density in FF and oocyte developmental potency suggests the possibility to use the floating cell density as a simple and non-invasive marker for oocyte quality. It is concluded that the developmental potential of an oocyte is determined by multifactor interactions, and multiple factors must be considered together to accurately predict the quality of an oocyte.
\end{abstract}

Reproduction (2006) 132 749-758

\section{Introduction}

A number of studies have shown that in vitro development of pre-implantation stage mammalian embryos is better when cultured in groups (group culture) than cultured singly in microdrops (microdrop individual culture, MIC) (Gardner et al. 1994, Kato \& Tsunoda 1994, Keefer et al. 1994, Moessner \& Dodson 1995). However, apart from the large-scale production of embryos for experimental purposes, most commercial and human embryo culture systems require culturing individually or in small groups. The reason for this need is the small number of oocytes available (ovum pick-up (OPU) technology, single slaughtered valuable oocyte donors and human IVF) or the required identification after culture. Besides, sometimes zona-free eggs must be cultured in isolation from each other to prevent conglomeration. Therefore, the establishment of an individual culture system that is as efficient as group culture has become of prime importance. Furthermore, although there are quite a few reports on individual culture of embryos, studies on individual culture of oocytes during maturation are few and with conflicting results (Carolan et al. 1996, Hagemann et al. 1998, Jewgenow et al. 1999, Ward et al. 2000).

Follicular oocytes obtained from slaughtered animals have been found highly variable in their developmental competence after in vitro maturation (IVM; Gordon \& Lu 1990, Bilodeau-Goeseels \& Panich 2002). Accurate, fast, and non-invasive markers of oocyte quality are therefore in urgent need for oocyte selection prior to IVM. Traditional methods have relied upon the measurement of follicle diameter and the morphological assessment of cumulus-ocyte complexes (COCs). Although several studies have shown that overall, oocytes from larger follicles have a greater developmental potential to the blastocyst stage in vitro (Pavlok et al. 1992, Lonergan 
et al. 1994, Blondin \& Sirard 1995, Blondin et al. 1997), diameter does not necessarily indicate whether the follicle is healthy and growing or undergoing atresia. Although COCs morphological assessment is undoubtedly popular, its accuracy as a forecaster of oocyte quality is still uncertain (Blondin \& Sirard 1995, Hazeleger et al. 1995, Jewgenow et al. 1999, Ebner et al. 2003).

It is recognized that apoptotic cell death is an underlying mechanism of cell loss during follicular atresia (Tilly et al. 1991, Hsueh et al. 1994, Liu et al. 2003, Yu et al. 2003, 2004). While the detection of granulosa cells (GCs) apoptosis has been widely used to identify atretic follicles, very little evidence for its use as a marker of oocyte quality exists. The effect of follicular cell apoptosis on oocyte developmental competence should be best studied by individual culture that demonstrates a functional relationship between follicular origin and quality of oocytes. However, studies in this field are few and results are discrepant. With MIC systems, some studies indicated that reduced oocyte developmental capacity was related to apoptotic death of follicular cells even before morphological signs of severe atresia were detected (Jewgenow et al. 1999), but others suggested that even a high degree of atresia was not necessarily detrimental (Hagemann et al. 1999). Therefore, the effect of follicular cell apoptosis on oocyte developmental potential must be studied using an individual culture system that is as efficient and consistent as group culture. In addition, most of the above reviewed studies were conducted on cattle or other animals, not on goats.

In this study, we first established a well-in-drop (WID) system for individual oocyte/embryo culture and proved that the system was as efficient as group culture. We then studied the effects of GCs apoptosis, density of GCs in follicular fluid (FF), follicle size, COC morphology, and cumulus expansion on the developmental competence of goat oocytes using this system. We found that the developmental competence of oocytes with the same COC morphology and follicle size and the same grade of cumulus expansion may differ significantly with the level of GCs apoptosis. However, at the same level of atresia, oocyte developmental capacity may vary with follicle size, COC morphology, or grades of cumulus expansion. This suggests that the developmental potential of an oocyte is determined by multifactor interactions, and multiple factors must be considered together to accurately predict the quality of an oocyte.

\section{Materials and Methods}

\section{Isolation of follicles and recovery of oocytes and GCS}

Goat ovaries were obtained from a local abattoir and transported within $3 \mathrm{~h}$ to the laboratory in sterilized saline containing $100 \mathrm{IU} / \mathrm{ml}$ penicillin and $0.05 \mathrm{mg} / \mathrm{ml}$ streptomycin and maintained at $30-35^{\circ} \mathrm{C}$. Ovaries in growth phase with neither corpus luteum nor follicles larger than $5 \mathrm{~mm}$ in diameter were selected. Follicles were dissected by forceps, freed of adherent stromal tissue, and processed individually in $100 \mu \mathrm{l}$ Dulbecco's PBS (D-PBS) drops under a stereomicroscope. After their diameters were recorded to the nearest $0.1 \mathrm{~mm}$ with the aid of an eyepiece graticule, follicles were opened with forceps to remove COCs and GCs. The released COCs were characterized for morphological quality, picked up, and processed as described below. Follicles were then bisected and GCs on the interior wall were gently scraped into D-PBS.

The COCs recovered were divided into four grades according to the surrounding cumulus cells and quality of oocytes. Grade A, with four or more layers of cumulus cells; grade $B$, with one to three layers of cumulus cells; grade $\mathrm{C}$, completely or partially denuded; and grade $\mathrm{D}$, all others, including those with expanded cumulus and degenerated oocytes (Hashimoto et al. 1999). Only grades A and B oocytes from follicular growth stage ovaries were used unless otherwise specified.

\section{Assessment of GCs apoptosis}

The drop of D-PBS with GCs was collected into a $1.5 \mathrm{ml}$ tube on ice. Free floating GCs were separated from FF and D-PBS by centrifugation $(200 \times \mathbf{g}, 5 \mathrm{~min})$ at $4{ }^{\circ} \mathrm{C}$. For Hoechst 33342 staining, the GCs pellets were re-suspended in $50 \mu \mathrm{l}$ D-PBS supplemented with $0.01 \mathrm{mg} / \mathrm{ml}$ Hoechst 33342 (Sigma) and stained in dark for $5 \mathrm{~min}$. Ten microliters drop of suspension were then smeared on the slide and observed under a fluorescence microscope (1000X, under oil immersion). Cells with pycnotic nuclei (shrunken nuclei with a bright fluorescence appearance resulting from condensed chromatin) were considered as apoptotic (Fig. 1A, Shiota et al. 2003, Chen et al. 2005). Four to six fields of each slide were examined, and 200 GCs on each slide were analyzed to evaluate the degree of apoptosis of a follicle. Classes of follicles were determined as non-atretic with $<5 \%$ pycnotic nuclei, early atretic with $5-30 \%$ pycnotic nuclei, mid-atretic with $30-50 \%$ pycnotic nuclei, and late atretic with $>50 \%$ pycnotic nuclei.

For hematoxylin staining, the GCs pellets were re-suspended in $100 \mu \mathrm{l} 4 \%$ paraformaldehyde and prefixed for $20 \mathrm{~min}$ at room temperature. At the end of pre-fixation, a drop of the suspension was smeared on a slide and allowed to dry. The procedures used for hematoxylin staining were those for the conventional hematoxylin-eosin (HE) staining described in the textbook (Brauer 1955) with minor modifications. The stained cells were observed under a light microscope. Cells with heavily stained, shrunken nuclei, or apoptotic bodies were considered as apoptotic (Fig. 1B, Liu et al. 2003). 

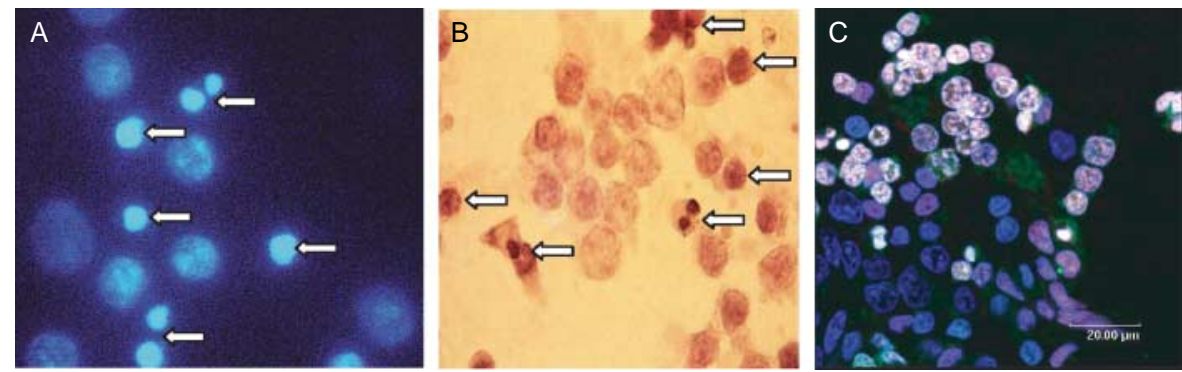

Figure 1 Goat granulosa-cell smears stained by different methods. A is a smear stained with Hoechst 33342, in which the apoptotic cells (arrows) showed shrunken nuclei with a bright fluorescence appearance under a fluorescence microscope (magnification, $\times 1000$ ). B is a smear stained with hematoxylin, in which the apoptotic cells showed heavily stained, shrunken nuclei, or apoptotic bodies (arrows) under a light microscope (magnification, $\times 1000$ ). C is a merged picture of a smear triple-stained with Annexin $\mathrm{V}, \mathrm{Pl}$, and Hoechst 33342, in which the apoptotic and necrotic cells appeared pink or white (bar $=20 \mu \mathrm{m})$.

For triple staining with Annexin $\mathrm{V}, \mathrm{Pl}$, and Hoechst 33342, the GCs pellets were re-suspended in $100 \mu \mathrm{l}$ binding buffer $\left(150 \mathrm{mM} \mathrm{NaCl}, 5 \mathrm{mM} \mathrm{KCl}, 1 \mathrm{mM} \mathrm{MgCl}_{2}\right.$, $1.8 \mathrm{mM} \mathrm{CaCl}_{2}, 10 \mathrm{mM}$ Hepes, $\mathrm{pH}$ 7.4) and centrifuged at $200 \times \mathbf{g}$ for $5 \mathrm{~min}$. Then, the cell pellets were re-suspended in $10 \mu \mathrm{l}$ buffer, $0.5 \mu \mathrm{l}$ Annexin V-FITC solution (Sigma), $1 \mu \mathrm{l} \mathrm{Pl}$ solution $(100 \mu \mathrm{g} / \mathrm{ml}$ in PBS), and $1 \mu \mathrm{l}$ Hoechst 33342 solution $(0.1 \mathrm{mg} / \mathrm{ml}$ in PBS) and incubated for $10 \mathrm{~min}$ at room temperature. At the end of incubation, the cells were washed by centrifugation, smeared on a slide and observed under a Leica laser scanning confocal system (TCS SP2). Hoechst 33342 labeled nuclear chromatin was excited with the $405 \mathrm{~nm}$ line of a diode laser. The fluorescein isothiocyanate (FITC) and propidium iodine (PI) fluorescence was obtained by excitation with $488 \mathrm{~nm}$ line of an $\mathrm{Ar} / \mathrm{ArHr}$ laser and the emitted light was passed through a $488 \mathrm{~nm}$ filter. The individual optical sections were pseudocolored and digitally recombined into a single composite image using the Leica Confocal Software. In the merged picture, while the healthy cells looked blue, the apoptotic and necrotic cells appeared pink or white (Fig. 1C).

\section{Assessment of GCs density in follicular fluid}

After washing thrice in D-PBS, each follicle was opened under a stereomicroscope with fine forceps in a D-PBS droplet of appropriate volume, carefully avoiding mural GCs fell off because of mechanical damage. Mural GCs that fell off by any chance were carefully removed by a mouth pipette. The resulted suspension was placed on a cytometer for floating GCs density assessment.

To determine the volume of D-PBS droplets used for collection of GCs from individual follicles, we measured the volume of FF from follicles of different sizes, and found a significant positive correlation between the volume of FF and the diameter of follicles $(r=0.95$, $P<0.01)$. A regression analysis established the following two equations for calculation of FF volume from follicles of different sizes: $v=8.9 d-17.0$ (when $d>2.5 \mathrm{~mm}), \quad v=3.8 d-4.7$ (when $1.5 \mathrm{~mm} \leq d \leq 2.5 \mathrm{~mm}$ ).

Here, $v=\mathrm{FF}$ volume $(\mu \mathrm{l})$ and $d=$ follicle diameter $(\mathrm{mm})$. Since, only follicles larger than $2.5 \mathrm{~mm}$ in diameter showed no mural GCs detachment and can hence be used for FF floating cell density measurement (see Results for details), and because a big deviation in FF volume was noticed among follicles in this group, the volumes of droplets for FF collection from these follicles were determined in three groups: $40 \mu \mathrm{l}$ D-PBS was used to dilute $6-10 \mu \mathrm{lFF}$ from 2.5 to $2.9 \mathrm{~mm}$ follicles, $60 \mu \mathrm{l}$ D-PBS was used for $10-12 \mu \mathrm{lFF}$ from 3.0 to $3.4 \mathrm{~mm}$ follicles, and $80 \mu \mathrm{l} \mathrm{D-PBS}$ for $13-18 \mu \mathrm{lFF}$ from 3.5 to $3.9 \mathrm{~mm}$ follicles.

\section{Preparation of the WID}

Two kinds of WIDs were used for experiments. The WID for IVM was large with approximately $0.9 \mathrm{~mm}$ width and $0.5 \mathrm{~mm}$ depth. The WID for embryo culture was small with approximately $0.5 \mathrm{~mm}$ width and $0.3 \mathrm{~mm}$ depth. A fire-polished solid glass rod was heated on a flame for approximately $2 \mathrm{~s}$, and then pressed slightly by hand to the bottom of a $35 \mathrm{~mm}$ polystyrene dish. The plastic melted immediately, and the rod was slightly immersed. After 15-20 s, the plastic became solidified and the rod was removed. In the WID system, 10 large wells and 20 small wells were made in each group for IVM and embryo culture, respectively. The wells were then filled with D-PBS supplemented with $0.1 \%$ of polyvinyl alcohol (PVA, Sigma Chemical Co., St Louis, MO, USA), and rigorously flushed by pipetting to remove air bubbles and possible toxic material arising from the melting process. The D-PBS was subsequently replaced with culture medium, which covered all the 10 large wells with $100 \mu \mathrm{l}$ droplets or the 20 small wells with $50 \mu \mathrm{l}$ droplets, covered with mineral oil and incubated overnight at $38.5{ }^{\circ} \mathrm{C}$ under $5 \% \mathrm{CO}_{2}$ in humidified air. After another rigorous flushing of the wells, the medium was replaced by a new 100 or $50 \mu \mathrm{l}$ culture medium and used for culture. Oocytes or embryos were cultured 
singly in different wells, which were numbered from 1 to 10 or 1 to 20.

\section{In vitro maturation of oocytes}

The recovered COCs were washed thrice in D-PBS and once in the culture medium before culture. Then, the COCs were put in WIDs for IVM (each per well). The culture medium was TCM-199 (Gibco, Grand Island, NY, USA) supplemented with $10 \%$ (v/v) FCS (Gibco), $1 \mathrm{mg} / \mathrm{ml} 17 \beta$-estradiol, $24.2 \mathrm{mg} / \mathrm{l}$ sodium pyruvate, $0.05 \mathrm{IU} / \mathrm{ml} \mathrm{FSH}, 0.05 \mathrm{IU} / \mathrm{ml} \mathrm{LH}$, and $10 \mathrm{ng} / \mathrm{ml}$ EGF. Maturation culture was conducted at $38.5{ }^{\circ} \mathrm{C}$ under $5 \%$ $\mathrm{CO}_{2}$ in humidified air.

\section{Oocyte activation}

At the end of maturation culture, oocytes were examined and processed individually under a stereomicroscope. Their cumulus cells were stripped by pipetting in D-PBS containing $0.1 \%(\mathrm{w} / \mathrm{v})$ hyaluronidase (Sigma). Denuded oocytes with a polar body were selected and washed in D-PBS before activation treatments. The ionomycin and 6-DMAP stocks were prepared in dimethyl sulfoxide (DMSO) and diluted to the desired concentrations in CR1aa (Rosenkrans et al. 1993) supplemented with $3 \mathrm{mg} / \mathrm{ml} \mathrm{BSA} \mathrm{(Sigma)} \mathrm{and} \mathrm{5 \%} \mathrm{FCS} \mathrm{before} \mathrm{use.} \mathrm{Oocytes}$ were first exposed to $5 \mathrm{mM}$ ionomycin for $2 \mathrm{~min}$ at room temperature, and then, after being extensively washed in CR1 aa, they were incubated in CR1 aa containing $2 \mathrm{mM}$ 6-DMAP for $2 \mathrm{~h}$ at $38.5{ }^{\circ} \mathrm{C}$ under $5 \% \mathrm{CO}_{2}$ in humidified air (Lan et al. 2005).

\section{Culture of activated oocytes.}

Oocytes after activation treatment were co-cultured on cumulus cell monolayers (CCM) in CR1aa containing $3 \mathrm{mg} / \mathrm{ml} \mathrm{BSA}$ and $5 \%$ FCS. To prepare CCM, cumulus cells were collected from in vitro matured COCs and cultured in DMEM/F12 (Gibco) supplemented with 10\% FCS in the WID system for embryo culture. At $24 \mathrm{~h}$ of culture, the DMEM/F12 in WID drops with growing CCM were replaced with $50 \mu \mathrm{l}$ warmed CR1aa and equilibrated for $1 \mathrm{~h}$ prior to embryo culture. After activation treatments, oocytes were washed in CR1aa and transferred to WIDs (one oocyte per well) and incubated for 9 days at $38.5{ }^{\circ} \mathrm{C}$ under $5 \% \mathrm{CO}_{2}$ in humidified air. Half of the culture medium in each drop was renewed at 48-h intervals. At the end of co-culture, development was examined under a microscope and numbers of embryos developing to different stages were recorded.

All the procedures during maturation, activation, and embryo culture were conducted carefully to ensure developmental competence could be traced back to the oocyte's follicle of origin. To keep results constant, all the procedures including measurement of follicle diameter, assessment of GCs apoptosis, and density and grading of COCs, and cumulus expansion were performed by one person (the first author of the paper).

\section{Data analysis}

Statistical analyses were carried out by ANOVA using Statistical Package for Social Sciences 11.5 for Windows (SPSS, Inc., Chicago, IL, USA). Where necessary, data were transformed. Differences between treatment groups were evaluated with the Duncan multiple comparison test. Data are expressed as mean \pm S.E.M. and $P<0.05$ is considered significant.

\section{Results}

\section{Accuracy of Hoechst staining for assessment of GCs apoptosis}

GCs collected from the same follicle were divided into three parts and apoptosis were assayed by Hoechst 33342 staining, hematoxylin staining, and triple staining (with Annexin V, Pl, and Hoechst 33342) respectively. Among the follicles analyzed $(n=13)$, the average percentages of apoptotic granulosa cells (AGCs) revealed by triple staining, hematoxylin staining, and Hoechst staining were $38.5 \pm 3.6 \%$ (ranging from 11 to $59 \%$ ), $24.8 \pm 3.4 \%(0-38 \%)$, and $26 \pm 3.4 \%(1-38 \%)$ respectively (Fig. 2). Although the percentages of AGCs revealed by hematoxylin staining and Hoechst staining were lower than those detected by triple staining, the three sets of values were highly correlated, $r=0.89$ and 0.97 between Hoechst and hematoxylin and between Hoechst and triple staining respectively $(P<0.01)$. Considering that triple staining and hematoxylin staining are more time-consuming and/or costly, and Hoechst staining has been used with success for apoptosis detection (Shiota et al. 2003, Chen et al. 2005), Hoechst staining was chosen for this study.

\section{Maturation and embryo development of goat oocytes cultured under different systems}

Goat oocytes from 2 to $4 \mathrm{~mm}$ follicles were matured, activated, and embryos cultured singly in microdrops (1 oocyte/10 $\mu \mathrm{l}$ drop), in groups (10 oocytes/100 $\mu$ drop for maturation, 20 oocytes $/ 50 \mu$ drop for embryo culture) or in the WID system. Maturation rates did not differ $(P>0.05)$ among different culture systems (Table 1). While morula/blastocyst (M/B) rates (percent morulae/blastocysts of cleaved oocytes) did not differ between WID culture and group culture, percent cleaved oocytes decreased significantly and no embryos developed into $\mathrm{M} / \mathrm{Bs}$ when cultured singly in microdrops. 


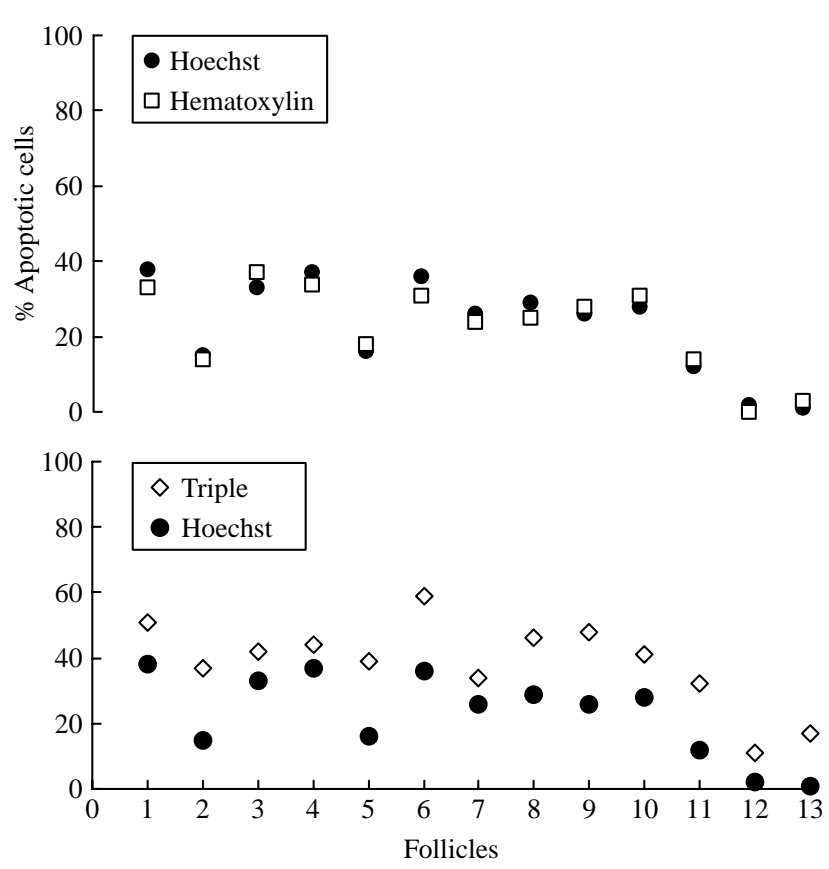

Figure 2 A graph with two scatter plots showing the percentages of apoptotic granulosa cells detected by Hoechst 33342 versus hematoxylin staining and Hoechst 33342 versus triple staining respectively, among 13 different follicles. The correlation coefficients are 0.97 and 0.89 between Hoechst and hematoxylin and between Hoechst and triple staining respectively. Correlation is significant at the 0.01 level in both cases.

\section{Effects of GCs apoptosis on oocyte developmental competence}

In the 1-1.4 mm follicle group, no oocytes from nonatretic follicles matured, but some matured and cleaved after activation when percent AGCs increased to above $15 \%$ (Table 2). In the 1.5-1.9 mm follicle group, maturation rates of oocytes were significantly higher in follicles with more than 30\% AGCs than in follicles with $<30 \%$ AGCs. The percentage of 8-16 cell embryos was significantly higher in follicles with $30-50 \%$ AGCs than in follicles with $<15 \%$ or more than $50 \%$ AGCs. In both the $2-2.9$ and $3-3.9 \mathrm{~mm}$ follicle groups, $\mathrm{M} / \mathrm{B}$ rates were significantly higher in early atretic follicles than in the non- or late atretic follicles. The overall rate of $\mathrm{M} / \mathrm{Bs}$ was lower in $2-2.9 \mathrm{~mm}$ follicles than in $3-3.9 \mathrm{~mm}$ follicles
(6.3 \pm 3.6 vs $15.9 \pm 5.1 \%, P=0.05)$. This indicated that (a) the majority of goat oocytes acquired competence for meiosis and development up to the $8-16$ cell stage in follicles larger than $2 \mathrm{~mm}$, but they did not gain the ability to form $\mathrm{M} / \mathrm{Bs}$ until follicles larger than $3 \mathrm{~mm}$ in diameter; (b) while moderate atresia was beneficial but severe atresia was detrimental to competent oocytes, atresia of different degrees was beneficial to the incompetent oocytes.

\section{Relationship between GCs apoptosis, cumulus expansion, and oocyte developmental competence}

The COCs were matured for $24 \mathrm{~h}$ before cumulus expansion was assessed under a microscope. Cumulus expansion was scored in $0-4$ grades. 0 , no response; 1 , minimum response, cells in the peripheral two layers began to expand; 2, expansion extended inwards to several layers of cumulus cells; 3 , expansion of all layers of the cumulus except corona radiata cells; and 4, expansion of the whole cumulus including corona radiata cells (Sun et al. 2002a). Cumulus expansion capacity of goat oocytes decreased with increasing apoptosis of GCs, but increased with follicle size. Thus, few oocytes from follicles with more than $30 \%$ AGCs or from follicles smaller than $2 \mathrm{~mm}$ in diameter underwent a cumulus expansion beyond grade 3 (Table 3 ). All the data in Table 3 were recorded from the same population of oocytes as used in Table 2.

The relationship between cumulus expansion and competence of oocytes from 2 to $4 \mathrm{~mm}$ follicles was analyzed using the data from Table 3 . Rates of $\mathrm{M} / \mathrm{Bs}$ were significantly higher in oocytes with grade 3 cumulus expansion than in those showing grade 2 or 1 cumulus expansion in follicles with 5-30\% AGCs (Table 4). Oocytes showing no cumulus expansion never formed M/Bs. Rates of M/Bs were significantly lower in oocytes from follicles with $<5 \%$ AGCs than in oocytes from follicles with 15-30\% AGCs in both grade 2 and grade 3 expansion groups. This indicates that oocyte developmental potential increases with increasing cumulus expansion, but oocytes showing the same grade of cumulus expansion may vary in their developmental competence with degrees of follicular atresia.

Table 1 Maturation and embryo development of goat oocytes from 2-4 mm follicles cultured under different systems.

\begin{tabular}{lccccc}
\hline & & & & \% Embryos developing to \\
\cline { 3 - 6 } Culture system & $\begin{array}{c}\text { Oocytes cultured } \\
\text { (replicates) }\end{array}$ & \% Oocytes matured & 2-Cell & 8-16 Cell & Mor/blast \\
\hline MIC & $33(3)$ & $77.4 \pm 4.3^{\mathrm{a}}$ & $61.7 \pm 2.5^{\mathrm{a}}$ & $26.2 \pm 5.0^{\mathrm{a}}$ & $0^{\mathrm{a}}$ \\
Group & $60(3)$ & $86.7 \pm 4.8^{\mathrm{a}}$ & $84.7 \pm 4.4^{\mathrm{b}}$ & $50.6^{\mathrm{b}} \pm 1.8^{\mathrm{b}}$ & $18.8 \pm 3.2^{\mathrm{b}}$ \\
WID & $60(3)$ & $88.3 \pm 3.3^{\mathrm{a}}$ & $79.1 \pm 4.3^{\mathrm{b}}$ & $52.5 \pm 4.9^{\mathrm{b}}$ & $14.2 \pm 3.6^{\mathrm{b}}$ \\
\hline
\end{tabular}

Values with common letters in their superscripts in the same column did not differ $(P>0.05)$. 
Table 2 Effects of granulosa cell apoptosis on development of goat oocytes from follicles of different sizes.

\begin{tabular}{|c|c|c|c|c|c|c|}
\hline \multirow[b]{2}{*}{$\begin{array}{l}\text { Follicle diameter } \\
(\mathrm{mm})\end{array}$} & \multirow[b]{2}{*}{$\%$ AGCs } & \multirow[b]{2}{*}{ Oocytes observed } & \multirow[b]{2}{*}{$\begin{array}{l}\% \text { Matured } \\
\text { oocytes }\end{array}$} & \multicolumn{3}{|c|}{$\%$ Embryos developing to } \\
\hline & & & & 2-Cell & 8-16 Cell & Mor/blast \\
\hline \multirow[t]{5}{*}{ 1.0-1.4 } & $<5$ & 25 & $0^{\mathrm{a}}$ & & & \\
\hline & $5-15$ & 21 & $0^{\mathrm{a}}$ & & & \\
\hline & $15-30$ & 23 & $26.1 \pm 9.3^{b}$ & $33.3 \pm 21.1^{\mathrm{a}}$ & $0^{\mathrm{a}}$ & \\
\hline & $30-50$ & 27 & $29.6 \pm 9.0^{\mathrm{b}}$ & $37.5 \pm 18.3^{\mathrm{a}}$ & $0^{\mathrm{a}}$ & \\
\hline & $>50$ & 21 & $33.3 \pm 10.5^{b}$ & $42.9 \pm 20.2^{\mathrm{a}}$ & $0^{\mathrm{a}}$ & \\
\hline \multirow[t]{5}{*}{$1.5-1.9$} & $<5$ & 43 & $37.2 \pm 7.5^{\mathrm{a}}$ & $43.8 \pm 12.8^{\mathrm{a}}$ & $0^{\mathrm{a}}$ & \\
\hline & $5-15$ & 35 & $40.0 \pm 8.4^{\mathrm{a}}$ & $50.0 \pm 13.9^{a}$ & $14.3 \pm 14.3^{\mathrm{a}}$ & $0^{\mathrm{a}}$ \\
\hline & $15-30$ & 33 & $39.4 \pm 8.6^{\mathrm{a}}$ & $61.5 \pm 14.0^{\mathrm{a}}$ & $37.5 \pm 18.3^{\mathrm{a}, \mathrm{b}}$ & $0^{\mathrm{a}}$ \\
\hline & $30-50$ & 36 & $69.4 \pm 7.8^{\mathrm{b}}$ & $60.0 \pm 10.0^{\mathrm{a}}$ & $40.0 \pm 13.1^{b}$ & $6.7 \pm 6.7^{\mathrm{a}}$ \\
\hline & $>50$ & 32 & $65.6 \pm 8.5^{\mathrm{b}}$ & $57.1 \pm 11.1^{\mathrm{a}}$ & $16.7 \pm 11.2^{\mathrm{a}}$ & $0^{\mathrm{a}}$ \\
\hline \multirow[t]{5}{*}{$2.0-2.9$} & $<5$ & 55 & $81.8 \pm 5.2^{\mathrm{a}}$ & $80.0 \pm 6.0^{\mathrm{a}}$ & $33.3 \pm 8.0^{\mathrm{a}, \mathrm{b}}$ & $0^{\mathrm{a}}$ \\
\hline & $5-15$ & 65 & $83.1 \pm 4.7^{\mathrm{a}}$ & $83.3 \pm 5.1^{\mathrm{a}}$ & $44.4 \pm 7.5^{a, b}$ & $8.9 \pm 4.3^{\mathrm{a}, \mathrm{b}}$ \\
\hline & $15-30$ & 52 & $82.7 \pm 5.3^{\mathrm{a}}$ & $86.0 \pm 5.3^{\mathrm{a}}$ & $56.8 \pm 8.3^{b}$ & $18.9 \pm 6.5^{\mathrm{b}}$ \\
\hline & $30-50$ & 49 & $75.5 \pm 6.2^{\mathrm{a}}$ & $73.0 \pm 7.4^{\mathrm{a}, \mathrm{b}}$ & $33.3 \pm 9.2^{\mathrm{a}, \mathrm{b}}$ & $3.7 \pm 3.7^{\mathrm{a}}$ \\
\hline & $>50$ & 41 & $73.2 \pm 7.0^{\mathrm{a}}$ & $56.7 \pm 9.2^{\mathrm{b}}$ & $23.5 \pm 10.6^{a}$ & $0^{a}$ \\
\hline \multirow[t]{5}{*}{$3.0-3.9$} & $<5$ & 78 & $85.9 \pm 4.0^{\mathrm{a}}$ & $88.1 \pm 4.0^{\mathrm{a}}$ & $37.3 \pm 6.4^{\mathrm{a}}$ & $3.4 \pm 2.4^{\mathrm{a}}$ \\
\hline & $5-15$ & 71 & $84.5 \pm 4.3^{\mathrm{a}}$ & $88.3 \pm 4.2^{\mathrm{a}}$ & $60.4 \pm 6.8^{\mathrm{b}}$ & $30.2 \pm 6.4^{\mathrm{b}}$ \\
\hline & $15-30$ & 63 & $77.8 \pm 5.3^{\mathrm{a}}$ & $79.6 \pm 5.8^{\mathrm{a}}$ & $61.5 \pm 7.9^{\mathrm{b}}$ & $25.6 \pm 7.1^{\mathrm{b}, \mathrm{c}}$ \\
\hline & $30-50$ & 61 & $73.8 \pm 5.7^{\mathrm{a}}$ & $75.6 \pm 6.5^{\mathrm{a}, \mathrm{b}}$ & $38.2 \pm 8.5^{\mathrm{a}}$ & $11.8 \pm 5.6^{\mathrm{a}, \mathrm{c}}$ \\
\hline & $>50$ & 53 & $73.6 \pm 6.1^{\mathrm{a}}$ & $61.5 \pm 7.9^{\mathrm{b}}$ & $29.2 \pm 9.5^{\mathrm{a}}$ & $8.3 \pm 5.8^{\mathrm{a}}$ \\
\hline
\end{tabular}

Values with common letters in their superscripts in the same column within follicle size group did not differ $(P>0.05)$.

Correlation of floating cell density in the follicular fluid with oocyte developmental capacity

When follicles of different diameters were opened under a stereomicroscope, antral layers of mural GCs detached from many (26-40\%) of the follicles smaller than $2.4 \mathrm{~mm}$ in diameter, but this seldom occurred in the larger follicles (data not shown). Regardless of the degree of atresia, $73-84 \%$ of the floating cells in the FF of 2.5-4 mm follicles underwent apoptosis and the difference in percentages of AGCs in FF was insignificant between the non-atretic and atretic follicles (data not shown).
We then analyzed the relationship between the density of floating FF cells and the developmental competence of oocytes from 2.5 to $4 \mathrm{~mm}$ follicles. As shown in Table 5, the percentage of $\mathrm{M} / \mathrm{Bs}$ was higher significantly $(P<0.05)$ in follicles with $7.5-12.5 \times 10^{6}$ floating FF cells than in follicles with $<2.5$ or $>25 \times 10^{6}$ floating cells, and it was higher also than in follicles with $2.5-7.5$ or $12.5-25 \times 10^{6}$ floating cells $(P=0.052$ and 0.051 respectively). A correlation analysis on the data presented in Table 5 showed that the percentages of apoptotic GCs were highly correlated with the concentrations of floating FF cells $(r=0.7, P<0.01)$.

Table 3 Effects of granulosa cell apoptosis on cumulus expansion of oocytes from follicles of different sizes.

\begin{tabular}{|c|c|c|c|c|c|c|c|}
\hline \multirow[b]{2}{*}{$\begin{array}{l}\text { Follicle diameter } \\
(\mathrm{mm})\end{array}$} & \multirow[b]{2}{*}{$\%$ AGCs } & \multirow[b]{2}{*}{$\begin{array}{c}\text { Oocytes } \\
\text { observed }^{\mathrm{a}}\end{array}$} & \multicolumn{5}{|c|}{$\%$ Oocytes with different grades of cumulus expansion } \\
\hline & & & 0 & 1 & 2 & 3 & 4 \\
\hline \multirow[t]{5}{*}{$1.0-1.9$} & $<5$ & 60 & $25.0 \pm 5.6^{\mathrm{b}}$ & $35.0 \pm 6.2^{\mathrm{b}}$ & $31.7 \pm 6.1^{b}$ & $8.3 \pm 3.6^{\mathrm{b}}$ & $0^{b}$ \\
\hline & $5-15$ & 52 & $34.6 \pm 6.7^{\mathrm{b}, \mathrm{c}}$ & $32.7 \pm 6.6^{b}$ & $28.8 \pm 6.3^{\mathrm{b}}$ & $3.8 \pm 2.7^{\mathrm{b}}$ & $0^{b}$ \\
\hline & $15-30$ & 48 & $47.9 \pm 5.0^{\mathrm{C}}$ & $47.9 \pm 7.3^{\mathrm{b}}$ & $4.2 \pm 2.9^{\mathrm{C}}$ & $0^{b}$ & $0^{\mathrm{b}}$ \\
\hline & $30-50$ & 38 & $55.3 \pm 8.2^{\mathrm{c}}$ & $44.7 \pm 8.2^{b}$ & $0^{\mathrm{c}}$ & $0^{\mathrm{b}}$ & $0^{\mathrm{b}}$ \\
\hline & $>50$ & 24 & $54.2 \pm 10.4^{\mathrm{c}}$ & $45.8 \pm 10.4^{\mathrm{b}}$ & $0^{\mathrm{C}}$ & $0^{\mathrm{b}}$ & $0^{\mathrm{b}}$ \\
\hline \multirow[t]{5}{*}{$2.0-2.9$} & $<5$ & 51 & $3.9 \pm 2.7^{\mathrm{b}}$ & $9.8 \pm 4.2^{\mathrm{b}}$ & $23.5 \pm 6.0^{b}$ & $56.9 \pm 7.0^{\mathrm{b}}$ & $5.9 \pm 3.3^{b}$ \\
\hline & $5-15$ & 54 & $9.3 \pm 4.0^{b, c}$ & $16.7 \pm 5.1^{b}$ & $25.9 \pm 6.0^{b}$ & $48.1 \pm 6.9^{b, c}$ & $0^{\mathrm{b}}$ \\
\hline & $15-30$ & 48 & $18.8 \pm 5.7^{\mathrm{c}}$ & $14.6 \pm 5.1^{b}$ & $27.1 \pm 6.5^{\mathrm{b}}$ & $39.6 \pm 7.1^{\mathrm{c}}$ & $0^{\mathrm{b}}$ \\
\hline & $30-50$ & 41 & $34.1 \pm 7.4^{\mathrm{d}}$ & $36.6 \pm 7.5^{b, c}$ & $26.8 \pm 6.9^{b}$ & $2.4 \pm 2.4^{\mathrm{d}}$ & $0^{\mathrm{b}}$ \\
\hline & $>50$ & 35 & $54.3 \pm 8.5^{\mathrm{e}}$ & $22.9 \pm 7.2^{\mathrm{C}}$ & $22.9 \pm 7.2^{b}$ & $0^{\mathrm{d}}$ & $0^{\mathrm{b}}$ \\
\hline \multirow[t]{5}{*}{$3.0-3.9$} & $<5$ & 71 & $0^{\mathrm{b}}$ & $0^{\mathrm{b}}$ & $23.9 \pm 5.1^{b}$ & $63.4 \pm 5.8^{\mathrm{b}}$ & $12.7 \pm 4.8^{\mathrm{b}}$ \\
\hline & $5-15$ & 65 & $3.1 \pm 2.2^{b, c}$ & $12.3 \pm 4.1^{\mathrm{b}, \mathrm{c}}$ & $26.2 \pm 5.5^{\mathrm{b}}$ & $50.8 \pm 6.2^{b, c}$ & $7.7 \pm 1.0^{\mathrm{b}, \mathrm{c}}$ \\
\hline & $15-30$ & 59 & $11.9 \pm 4.3^{\mathrm{c}}$ & $18.6 \pm 5.1^{c, d}$ & $23.7 \pm 5.6^{\mathrm{b}}$ & $42.4 \pm 6.5^{\mathrm{c}}$ & $3.4 \pm 1.3^{\mathrm{b}, \mathrm{c}}$ \\
\hline & $30-50$ & 54 & $31.5 \pm 6.4^{\mathrm{d}}$ & $27.8 \pm 6.2^{\mathrm{d}}$ & $29.6 \pm 6.3^{b}$ & $11.1 \pm 4.3^{\mathrm{d}}$ & $0^{\mathrm{c}}$ \\
\hline & $>50$ & 32 & $46.9 \pm 9.0^{\mathrm{e}}$ & $31.3 \pm 8.3^{\mathrm{d}}$ & $21.9 \pm 7.4^{b}$ & $\overline{0}^{\mathrm{d}}$ & $0^{\mathrm{c}}$ \\
\hline
\end{tabular}

Values with common letters in their superscript (b-e) in the same column within follicle size group did not differ $(P>0.05)$.

${ }^{a}$ All the data were recorded from the same population of oocytes used in Table 2. 
Table 4 Effects of cumulus expansion on maturation and development of oocytes from 2-4 mm follicles.

\begin{tabular}{|c|c|c|c|c|c|c|}
\hline \multirow[b]{2}{*}{ Cumulus expansion } & \multirow[b]{2}{*}{$\%$ AGCs } & \multirow[b]{2}{*}{ Oocytes cultured $^{\mathrm{a}}$} & \multirow[b]{2}{*}{$\begin{array}{l}\% \text { Oocytes } \\
\text { matured }\end{array}$} & \multicolumn{3}{|c|}{$\%$ Embryos developing to } \\
\hline & & & & 2-Cell & 8-16 Cell & Mor/blast \\
\hline \multirow[t]{4}{*}{0} & $\begin{array}{c}<5 \\
5-15\end{array}$ & $\begin{array}{l}0^{b} \\
7^{b}\end{array}$ & & & & \\
\hline & $15-30$ & 16 & $50.0 \pm 12.9^{c}$ & $37.5 \pm 18.3^{\mathrm{c}}$ & $0^{\mathrm{c}}$ & \\
\hline & $30-50$ & 31 & $48.4 \pm 9.1^{\mathrm{c}}$ & $33.3 \pm 12.6^{\mathrm{c}}$ & $0^{\mathrm{c}}$ & \\
\hline & $>50$ & 34 & $41.2 \pm 8.6^{\mathrm{c}}$ & $21.4 \pm 11.4^{\mathrm{c}}$ & $0^{\mathrm{c}}$ & \\
\hline \multirow[t]{5}{*}{1} & $<5$ & $5^{b}$ & & & & \\
\hline & $5-15$ & 17 & $76.5 \pm 10.5^{d}$ & $84.6 \pm 10.4^{\mathrm{d}, \mathrm{e}}$ & $45.5 \pm 15.7^{c, d}$ & $9.1 \pm 9.1^{\mathrm{c}}$ \\
\hline & $15-30$ & 18 & $83.3 \pm 9.0^{\mathrm{d}}$ & $80.0 \pm 10.7^{\mathrm{d}, \mathrm{e}}$ & $41.7 \pm 14.7^{\mathrm{c}, \mathrm{d}}$ & $8.3 \pm 8.3^{c}$ \\
\hline & $30-50$ & 30 & $76.7 \pm 7.9^{\mathrm{d}}$ & $73.9+9.4^{\mathrm{d}, \mathrm{e}}$ & $35.3+11.9^{c, d}$ & $0^{\mathrm{C}}$ \\
\hline & $>50$ & 18 & $77.8 \pm 10.1^{d}$ & $64.3 \pm 13.3^{\mathrm{d}}$ & $22.2 \pm 14.7^{c, d}$ & $0^{\mathrm{c}}$ \\
\hline \multirow[t]{5}{*}{2} & $<5$ & 29 & $89.7 \pm 5.8^{\mathrm{d}}$ & $80.8 \pm 7.9^{\mathrm{d}, \mathrm{e}}$ & $42.9 \pm 11.7^{c, d}$ & $4.8 \pm 4.8^{\mathrm{c}}$ \\
\hline & $5-15$ & 31 & $87.1 \pm 6.1^{\mathrm{d}}$ & $85.2 \pm 7.0^{\mathrm{d}, \mathrm{e}}$ & $56.5 \pm 10.6^{\mathrm{d}}$ & $13.0 \pm 7.2^{c, d}$ \\
\hline & $15-30$ & 27 & $88.9 \pm 6.2^{\mathrm{d}}$ & $83.3 \pm 7.8^{\mathrm{d}, \mathrm{e}}$ & $55.0 \pm 11.4^{\mathrm{d}}$ & $20.0 \pm 9.2^{\mathrm{d}, \mathrm{e}}$ \\
\hline & $30-50$ & 27 & $81.5 \pm 7.6^{\mathrm{d}}$ & $77.3 \pm 9.1^{\mathrm{d}, \mathrm{e}}$ & $47.1 \pm 12.5^{c, d}$ & $11.8 \pm 8.1^{c, d}$ \\
\hline & $>50$ & 15 & $80.0 \pm 10.7^{d}$ & $66.7 \pm 14.2^{d}$ & $37.5 \pm 18.3^{c, d}$ & $12.5 \pm 12.5^{\mathrm{c}, \mathrm{d}}$ \\
\hline \multirow[t]{5}{*}{3} & $<5$ & 74 & $87.8 \pm 3.8^{\mathrm{d}}$ & $93.8 \pm 3.0^{\mathrm{e}, \mathrm{f}}$ & $45.9 \pm 6.4^{\mathrm{c}, \mathrm{d}}$ & $1.6 \pm 1.6^{\mathrm{c}}$ \\
\hline & $5-15$ & 59 & $89.8 \pm 4.0^{\mathrm{d}}$ & $96.2 \pm 2.6^{f}$ & $70.6 \pm 6.4^{\mathrm{d}}$ & $39.2 \pm 6.9^{\mathrm{e}}$ \\
\hline & $15-30$ & 44 & $81.8 \pm 5.9^{\mathrm{d}}$ & $91.7 \pm 4.7^{\mathrm{e}, \mathrm{f}}$ & $63.6 \pm 8.5^{\mathrm{d}}$ & $33.3 \pm 8.3^{\mathrm{e}}$ \\
\hline & $30-50$ & $7^{b}$ & & & & \\
\hline & $>50$ & $0^{b}$ & & & & \\
\hline
\end{tabular}

Values with common letters in their superscript $(c-f)$ in the same column did not differ $(P>0.05)$.

${ }^{\mathrm{a}}$ Data were from the oocytes used in Table $3 .{ }^{\mathrm{b}}$ Data were not enough to be analyzed.

\section{Effects of GCs apoptosis on COCs morphology}

Distribution of the four type COCs in $2-4 \mathrm{~mm}$ follicles with different percentages of AGCs are summarized in Table 6. In general, proportions of grade A COCs decreased, while those of grades B, C, and D increased with increasing apoptosis of GCs, but it was only in follicles with over $30 \%$ AGCs that the decrease in grade $A$ and the increase in grade D COCs became significant $(P<0.05)$.

\section{Discussion}

We showed in this study that MIC of goat oocytes during maturation and embryo culture did not affect maturation but impaired embryo development. In mice (Paria \& Dey 1990, Canseco et al. 1992), sheep (Gardner et al. 1994), cattle (Blondin \& Sirard 1995, Carolan et al. 1996, O'Doherty et al. 1997, Ward et al. 2000), and human (Moessner \& Dodson 1995), oocytes cultured in groups have better developmental competence than oocytes cultured singly. However, when goat oocytes were matured and embryos cultured in the WID system, rates of cleavage and $\mathrm{M} / \mathrm{Bs}$ were comparable with those obtained in group culture in the same drop size and at the same embryo density. Vajta et al. (2000) reported similar results with culture of bovine zygotes using a similar system (the well of the well (WOW) system). This indicates that the WID system we have developed can best mimic group culture in efficiency, while allows identification of oocyte origin.

Our previous studies have shown that GCs apoptosis is an underlying mechanism of follicular atresia in the goat (Yu et al. 2003, 2004) as in other animals (Liu et al. 2003). Most of the studies on the effect of GCs apoptosis on oocyte developmental competence have so far been conducted in the bovine and using group culture systems. No such studies have been reported in the goat. Using the MIC system, while Jewgenow et al. (1999) concluded that reduced oocyte developmental capacity was related to apoptotic death of follicular cells even before morphological signs of severe atrsia were

Table 5 Relationship between granulosa cell density in follicular fluid (FF) and oocyte developmental competence.

\begin{tabular}{lccccc}
\hline & & & & \% Embryos developing to \\
\cline { 3 - 6 } $\begin{array}{l}\text { FF cell density } \\
\left(\times 10^{6} / \mathrm{ml}\right)\end{array}$ & Follicles observed & $\%$ Oocytes matured & 2-Cell & 8-16 Cell & Mor/blast \\
\hline$<2.5$ & 42 & $76.2 \pm 6.7^{\mathrm{a}}$ & $81.3 \pm 7.0^{\mathrm{a}, \mathrm{b}}$ & $42.3 \pm 9.9^{\mathrm{a}, \mathrm{b}}$ & $7.7 \pm 5.3^{\mathrm{b}}$ \\
$2.5-7.5$ & 47 & $93.6 \pm 3.6^{\mathrm{b}}$ & $86.4 \pm 5.2^{\mathrm{a}, \mathrm{b}}$ & $50.0 \pm 8.2^{\mathrm{a}, \mathrm{b}}$ & $13.2 \pm 5.6^{\mathrm{a}, \mathrm{b}}$ \\
$7.5-12.5$ & 42 & $95.2 \pm 3.3^{\mathrm{b}}$ & $95.0 \pm 3.5^{\mathrm{a}}$ & $55.3 \pm 8.2^{\mathrm{a}}$ & $28.9 \pm 7.5^{\mathrm{a}}$ \\
$12.5-25$ & 38 & $81.6 \pm 6.4^{\mathrm{a}, \mathrm{b}}$ & $83.9 \pm 6.7^{\mathrm{a}, \mathrm{b}}$ & $38.5 \pm 9.7^{\mathrm{a}, \mathrm{b}}$ & $11.5 \pm 6.4^{\mathrm{a}, \mathrm{b}}$ \\
$>25$ & 36 & $80.6 \pm 6.7^{\mathrm{a}, \mathrm{b}}$ & $72.4 \pm 8.4^{\mathrm{b}}$ & $28.6 \pm 10.1^{\mathrm{b}}$ & $4.8 \pm 4.8^{\mathrm{b}}$ \\
\hline
\end{tabular}

Values with common letters in their superscripts in the same column did not differ $(P>0.05)$. 
Table 6 Percentages of COCs of different grades in 2-4 mm follicles at different stages of atresia.

\begin{tabular}{|c|c|c|c|c|c|}
\hline \multirow[b]{2}{*}{$\%$ AGCs } & \multirow[b]{2}{*}{ Oocytes observed } & \multicolumn{4}{|c|}{$\%$ COCs of different grades } \\
\hline & & $A$ & $\mathrm{~B}$ & C & $\mathrm{D}$ \\
\hline$<5$ & 178 & $89.8 \pm 2.3^{\mathrm{a}}$ & $7.3 \pm 2.0^{\mathrm{a}}$ & $2.8 \pm 1.2^{\mathrm{a}}$ & $0^{\mathrm{a}}$ \\
\hline $5-15$ & 171 & $77.8 \pm 3.2^{\mathrm{b}}$ & $11.6 \pm 2.5^{\mathrm{a}, \mathrm{b}}$ & $7.6 \pm 2.0^{\mathrm{a}}$ & $2.9 \pm 1.3^{\mathrm{a}}$ \\
\hline $15-30$ & 183 & $73.8 \pm 3.3^{b}$ & $13.1 \pm 2.5^{\mathrm{a}, \mathrm{b}}$ & $8.2 \pm 2.0^{\mathrm{a}, \mathrm{b}}$ & $4.9 \pm 1.6^{\mathrm{a}}$ \\
\hline $30-50$ & 156 & $40.4 \pm 3.9^{c}$ & $16.0 \pm 3.0^{\mathrm{b}}$ & $14.1 \pm 2.8^{\mathrm{b}, \mathrm{c}}$ & $29.5 \pm 2.7^{b}$ \\
\hline$>50$ & 148 & $26.4 \pm 3.6^{\mathrm{d}}$ & $18.9 \pm 3.2^{b}$ & $15.5 \pm 3.0^{\mathrm{C}}$ & $39.2 \pm 4.0^{\mathrm{C}}$ \\
\hline
\end{tabular}

Values with common letters in their superscripts in the same column did not differ $(P>0.05)$.

detected, Hagemann et al. (1999) suggested that even a high degree of atresia was not necessarily detrimental to bovine oocytes. Using the WID culture system, we showed that while late atresia was detrimental, early atresia was beneficial to the competent oocytes. Previous studies have demonstrated that a low level of atresia tended to improve the in vitro competence of bovine oocytes (Blondin \& Sirard 1995, Moor et al. 1996, Hagemann et al. 1999, de Wit et al. 2000, Hendriksen et al. 2000). However, this study showed that atresia of all degrees was beneficial to the incompetent goat oocytes. The effect of atresia on incompetent oocytes has not been reported, but it is important for utilization of these oocytes.

A characteristic of cells undergoing apoptosis is that junctions with neighboring cells are disrupted (Duvall \& Wyllie 1986). Therefore, GCs from interior follicle wall will enter FF after apoptosis, which may reflect the degree of follicle atresia. In this study, $73-84 \%$ of the floating cells were found apoptotic in FF of $2.5-4 \mathrm{~mm}$ follicles, regardless of degrees of atresia. This indicates that not the apoptotic proportion of floating FF cells, but rather their concentration in the FF might reflect the atretic status of a follicle. Our correlation analysis showed a high correlation between the percentages of AGCs and the concentrations of floating FF cells. Furthermore, we showed that the density of floating cells in FF affected oocyte maturation and development significantly. Although this suggests that the floating cell density in FF can be used as a non-invasive marker of oocyte quality, its use would likely be restricted to large follicles because antral layers of mural GCs detached from many of the small follicles in both the bovine (Irving-Rodgers et al. 2001) and the goat (this study).

Both the present and the previous studies in cattle (Blondin \& Sirard 1995, de Wit et al. 2000, Zeuner et al. 2003) indicate a high correlation between follicle quality or GCs apoptosis and distribution of COCs with different morphology. Since, only grade A and B oocytes were used in this study, that oocytes from early atretic follicles showed a higher, while those from late atretic follicles a lower developmental potential suggested a high correlation between COCs morphology and oocyte competence. Studies on the bovine have also shown that COCs with good morphology tended to develop better in vitro, although some indicated that oocytes with incomplete cumulus developed as well (Madison et al. 1992, Blondin \& Sirard 1995, de Wit et al. 2000). However, both this and other studies showed that the COCs with good morphology could have come from the late atretic follicles and developed poorly (Jewgenow et al. 1999, de Wit et al. 2000). Although COCs with good morphology came mainly from the non- and early atretic follicles, COCs with poor morphology came nearly exclusively from the late atretic follicles (de Wit et al. 2000, the present study). In addition, although nonatretic follicles contained a high percentage of grade $\mathrm{A}$ COCs, oocytes from these follicles showed a lower developmental competence than those from early atretic follicles. Therefore, while COCs with advanced signs of degeneration are bound to have decreased potency to develop in vitro, the developmental potential of oocytes with good appearance is affected by factors other than morphology.

Goat oocytes from $<0.5 \mathrm{~mm}$ follicles were unable to undergo GVBD when matured in vitro. They became GVBD-competent in $0.5 \mathrm{~mm}$ follicles, Ml-competent in $1-1.8 \mathrm{~mm}$ follicles and MIl-competent in 2-5 mm follicles (De Smedt et al. 1994, Crozet et al. 1995, Ma et al. 2003). This study showed that the majority of goat oocytes acquired competence for development up to the 8-16 cell stage in follicles larger than $2 \mathrm{~mm}$, but did not gain the ability to form $\mathrm{M} / \mathrm{Bs}$ until follicles larger than $3 \mathrm{~mm}$ in diameter. Overall, these results agree with that bovine oocytes from larger follicles tend to develop better in vitro (Tan \& Lu 1990, Pavlok et al. 1992, Lonergan et al. 1994).

The present data indicate that both the follicle size and the level of atresia affect oocyte cumulus expansion during IVM. This has not been reported. The limited number of studies conducted so far indicates that, while not essential for nuclear maturation (Leibfried \& First 1979, Sun et al. 2002b, Han et al. 2006), cumulus expansion is important for successful fertilization (Ball et al. 1983, Chen et al. 1993, Qian et al. 2003), because unexpanded cumulus may present a barrier to sperm penetration (Bedirian et al. 1975). However, both Han et al. (2006) and this study showed that M/B rates were highly correlated with the degree of cumulus expansion in parthenogenetic goat oocytes, suggesting that cumulus expansion contributes not only to successful fertilization but also to embryo development. 
In summary, the developmental potency of goat oocytes with the same COC morphology, the same follicle size, and the same grade of cumulus expansion may differ significantly with the level of GCs apoptosis. However, at the same level of GCs apoptosis, oocyte developmental capacity may vary with follicle size, COC morphology, or grades of cumulus expansion. This suggests that the developmental potential of an oocyte is determined by multifactor interactions, and multiple factors must be considered simultaneously to accurately predict the quality of an oocyte. The correlation between floating FF cell density and oocyte development suggests the possibility to use the floating cell density in FF as a simple and non-invasive marker for oocyte quality.

\section{Acknowledgements}

This study was supported by grants from the Natural Science Foundation of China (nos 30170679, 30430530 and 30571337 ). The authors declare that there is no conflict of interest that would prejudice the impartiality of this scientific work.

\section{References}

Ball GD, Leibfried ML, Lenz RW, Ax RL, Bavister BD \& First NL 1983 Factors affecting successful in vitro fertilization of bovine follicular oocytes. Biology of Reproduction 28 717-725.

Bedirian KN, Shea BF \& Baker RD 1975 Fertilization of bovine follicular oocytes in bovine and porcine oviducts. Candian Journal of Animal Science $\mathbf{5 5}$ 251-256.

Bilodeau-Goeseels S \& Panich P 2002 Effects of oocyte quality on development and transcriptional activity in early bovine embryos. Animal Reproduction Science 71 143-155.

Blondin P \& Sirard MA 1995 Oocyte and follicular morphology as determining characteristics for developmental competence in bovine oocytes. Molecular Reproduction and Development 41 $54-62$.

Blondin P, Coenen K, Guilbault LA \& Sirard MA 1997 In vitro production of bovine embryos: developmental competence is acquired before maturation. Theriogenology 47 1061-1075.

Brauer A 1955 Staining and mounting. In Laboratory Directions for Histological Technique, pp 23-25. Ed. A Brauer. Minneapolis, MN: Burgess Publishing Company.

Canseco RS, Sparks AE, Pearson RE \& Gwazdauskas FC 1992 Embryo density and medium volume effects on early murine embryo development. Journal of Assisted Reproduction and Genetics 9 454-457.

Carolan C, Lonergan P, Khatir H \& Mermillod P 1996 In vitro production of bovine embryos using individual oocytes. Molecular Reproduction and Development 45 145-150.

Chen L, Russell PT \& Larsen WJ 1993 Functional significance of cumulus expansion in the mouse: roles for the preovulatory synthesis of hyaluronic acid within the cumulus mass. Molecular Reproduction and Development 34 87-93.

Chen Q, Yano T, Matsumi H, Osuga Y, Yano N, Xu J, Wada O, Koga K, Fujiwara T, Kugu K \& Taketani Y 2005 Cross-Talk between Fas/Fas ligand system and nitric oxide in the pathway subserving granulosa cell apoptosis: a possible regulatory mechanism for ovarian follicle atresia. Endocrinology 146 808-815.

Crozet N, Ahmed A \& Dubos MP 1995 Developmental competence of goat oocytes from follicles of different size categories following maturation, fertilization and culture in vitro. Journal of Reproduction of Fertility 105 293-298.
De Smedt V, Crozet N \& Gall L 1994 Morphological and functional changes accompanying the acquisition of meiotic competence of ovarian goat oocytes. Journal of Experimental Zoology 269 128-139.

de Wit AA, Wurth YA \& Kruip TA 2000 Effect of ovarian phase and follicle quality on morphology and developmental capacity of the bovine cumulus-oocyte complex. Journal of Animal Science $\mathbf{7 8}$ 1277-1283.

Duvall E \& Wyllie AH 1986 Death and the cell. Immunology Today 7 $115-118$.

Ebner T, Moser M, Sommergruber M \& Tews G 2003 Selection based on morphological assessment of oocytes and embryos at different stages of preimplantation development: a review. Human Reproduction Update 9 251-262.

Gardner DK, Lane M, Spitzer A \& Batt PA 1994 Enhanced rates of cleavage and development for sheep zygotes cultured to the blastocyst stage in vitro in the absence of serum and somatic cells: amino acids, vitamins, and culturing embryos in groups stimulate development. Biology of Reproduction 50 390-400.

Gordon I \& Lu KH 1990 Production of embryos in vitro and its impact on livestock production. Theriogenology 33 77-87.

Hagemann LJ, Weilert LL, Beaumont SE \& Tervit HR 1998 Development of bovine embryos in single in vitro production (sIVP) systems. Molecular Reproduction and Development $\mathbf{5 1}$ 143-147.

Hagemann LJ, Beaumont SE, Berg M, Donnison MJ, Ledgard A, Peterson AJ, Schurmann A \& Tervit HR 1999 Development during single IVP of bovine oocytes from dissected follicles: interactive effects of estrous cycle stage, follicle size and atresia. Molecular Reproduction and Development 53 451-458.

Han D, Lan GC, Wu YG, Han ZB, Wang HL \& Tan JH 2006 Factors affecting the efficiency and reversibility of roscovitine (ROS) block on the meiotic resumption of goat oocytes. Molecular Reproduction and Development 73 238-246.

Hashimoto S, Takakura R, Kishi M, Sudo T, Minami N \& Yamada M 1999 Ultrasound-guided follicle aspiration: the collection of bovine cumulus-oocyte complexes from ovaries of slaughtered or live cows. Theriogenology 51 757-765.

Hazeleger NL, Hill DJ, Stubbings RB \& Walton JS 1995 Relationship of morphology and follicular environment of bovine oocytes to their developmental potential in vitro. Theriogenology 43 509-522.

Hendriksen PJ, Vos PL, Steenweg WN, Bevers MM \& Dieleman SJ 2000 Bovine follicular development and its effect on the in vitro competence of oocytes. Theriogenology 53 11-20.

Hsueh AJW, Billig H \& Tsafriri A 1994 Ovarian follicle atresia: a hormonally controlled apoptotic process. Endocrine Reviews $\mathbf{1 5}$ 707-724.

Irving-Rodgers HF, van Wezel IL, Mussard ML, Kinder JE \& Rodgers RJ 2001 Atresia revisited: two basic patterns of atresia of bovine antral follicles. Reproduction 122 761-775.

Jewgenow K, Heerdegen B \& Muller K 1999 In vitro development of individually matured bovine oocytes in relation to follicular wall atresia. Theriogenology 51 745-756.

Kato Y \& Tsunoda Y 1994 Effects of the culture density of mouse zygotes on the development in vitro and in vivo. Theriogenology $\mathbf{4 1}$ $1315-1322$.

Keefer CL, Stice SL, Paprocki AM \& Golueke P 1994 In vitro culture of bovine IVM-IVF embryos: Cooperative interaction among embryos and the role of growth factors. Theriogenology 41 1323-1331.

Lan GC, Han D, Wu YG, Han ZB, Ma SF, Liu XY, Chang CL \& Tan JH 2005 Effects of duration, concentration, and timing of ionomycin and 6-dimethylaminopurine (6-DMAP) treatment on activation of goat oocytes. Molecular Reproduction and Development $\mathbf{7 1}$ 380-388.

Leibfried L \& First NL 1979 Characterization of bovine follicular oocytes and their ability to mature in vitro. Journal of Animal Science $4876-86$.

Liu ZH, Yue KZ, Ma SF, Sun XS \& Tan JH 2003 Effects of pregnant mare serum gonadotropin (eCG) on follicle development and granulosacell apoptosis in the pig. Theriogenology 59 775-785. 
Lonergan P, Monaghan P, Rizos D, Boland MP \& Gordon I 1994 Effect of follicle size on bovine oocyte quality and developmental competence following maturation, fertilization, and culture in vitro. Molecular Reproduction and Development 37 48-53.

Ma S, Lan G, Miao Y, Wang Z, Chang Z, Luo M \& Tan J 2003 Hypoxanthine (HX) inhibition of in vitro meiotic resumption in goat oocytes. Molecular Reproduction and Development 66 306-313.

Madison V, Avery B \& Greve T 1992 Selection of immature bovine oocytes for developmental potential in vitro. Animal Reproduction Science 27 1-11.

Moessner J \& Dodson WC 1995 The quality of human embryo growth is improved when embryos are cultured in groups rather than separately. Fertility and Sterility 64 1034-1035.

Moor RM, Lee C, Dai YF \& Fulka J Jr 1996 Antral follicles confer developmental competence on oocytes. Zygote 4 289-293.

O'Doherty EM, Wade MG, Hill J \& Boland MP 1997 Effects of culturing bovine oocytes either singly or in groups on development to blastocysts. Theriogenology 48 161-169.

Paria BC \& Dey SK 1990 Preimplantation embryo development in vitro: cooperative interactions among embryos and role of growth factors. PNAS 87 4756-4760.

Pavlok A, Lucas-Hahn A \& Niemann H 1992 Fertilization and developmental competence of bovine oocytes derived from different categories of antral follicles. Molecular Reproduction and Development 31 63-67.

Qian Y, Shi WQ, Ding JT, Sha JH \& Fan BQ 2003 Predictive value of the area of expanded cumulus mass on development of porcine oocytes matured and fertilized in vitro. Journal of Reproduction Development 49 167-174.

Rosenkrans CF Jr, Zeng GQ, MCNamara GT, Schoff PK \& First NL 1993 Development of bovine embryos in vitro as affected by energy substrates. Biology of Reproduction 49 459-462.

Shiota M, Sugai N, Tamura M, Yamaguchi R, Fukushima N, Miyano T \& Miyazaki H 2003 Correlation of mitogen-activated protein kinase activities with cell survival and apoptosis in porcine granulosa cells. Zoological Science 20 193-201.
Sun XS, Yue KZ, Ma SF, Yi YL, Zou Y \& Tan JH 2002a Sources of cumulus expansion enabling factor (CEEF) in porcine follicles. Chinese Science Bulletin 47 1619-1622.

Sun XS, Yue KZ, Ma SF, Liu ZH, Liu Y \& Tan JH 2002b Relationship between oocyte nuclear maturation and cumulus expansion. Scientia Agricultura Sinica 35 85-88.

Tan SJ \& Lu KH 1990 Effects of different estrous stages of ovaries and sizes of follicles on generation of bovine embryos in vitro. Theriogenology 33335.

Tilly JL, Kowalski KI, Johnson AL \& Hsueh AJ 1991 Involvement of apoptosis in ovary follicular atresia and postovulatory regression. Endocrinology 129 2799-2801.

Vajta G, Peura TT, Holm P, Paldi A, Greve T, Trounson AO \& Callesen H 2000 New method for culture of zona-included or zona-free embryos: the well of the well (WOW) system. Molecular Reproduction and Development 55 256-264.

Ward FA, Lonergan P, Enright BP \& Boland MP 2000 Factors affecting recovery and quality of oocytes for bovine embryo production in vitro using ovum pick-up technology. Theriogenology 54 433-446.

Yu Y, Li W, Han Z, Luo M, Chang Z \& Tan J 2003 The effect of folliclestimulating hormone on follicular development, granulosa cell apoptosis and steroidogenesis and its mediation by insulin-like growth factor-I in the goat ovary. Theriogenology 60 1691-1704.

Yu YS, Sui HS, Han ZB, Li W, Luo MJ \& Tan JH 2004 Apoptosis in granulosa cells during follicular atresia: relationship with steroids and insulin-like growth factors. Cell Research 14 341-346.

Zeuner A, Muller K, Reguszynski K \& Jewgenow K 2003 Apoptosis within bovine follicular cells and its effect on oocyte development during in vitro maturation. Theriogenology 59 1421-1433.

Received 5 June 2006

First decision 26 July 2006

Accepted 15 August 2006 